\title{
MONITORING WATER-CHEMISTRY EVOLUTION IN THE BENTONITE BUFFER USING MAGNETS: EFFECTS OF CORROSION ON BUFFER STABILITY
}

\author{
Nicola Rigonat $^{1}{ }^{1 *}$, Christian Mavris $^{2}$, Simon Harley $^{1}$, \\ and IAN B. BUTLER ${ }^{1}$ \\ ${ }^{1}$ The University of Edinburgh, Grant Institute of GeoSciences, James Hutton Road, \\ Edinburgh EH9 $3 F E$, UK \\ ${ }^{2}$ Department of Earth Science, Natural History Museum, Cromwell Road, \\ London SW7 5BD, UK \\ *e-mail: Nicola.Rigonat@ed.ac.uk
}

\begin{abstract}
Bentonite has been chosen as a buffer material by several national nuclear-waste management companies because of its swelling capacity and low water permeability, and because it retards the transport of radionuclides and corrosion products toward the geosphere. The aim of the present study was to develop a magnetic material that has the ability to detect changes in groundwater compositions in an underground nucleardeposit facility through variation in its magnetic properties with time.

The present study has investigated the effect of the corrosion of $\mathrm{NdFeB}$ magnets on the Na-bentonite buffer under different environmental conditions. Seven different aqueous solutions were used for long-time exposure tests $\left(70^{\circ} \mathrm{C}, 5\right.$ months) with fragments of $\mathrm{NdFeB}$ magnets and powdered Na-bentonite. The corrosion of $\mathrm{NdFeB}$ alloy had no detectable effect on the mineralogy of the clay minerals, and any change on the bentonite matrix, measured through X-ray diffraction analysis, was related to the different initial chemistry of the solutions.
\end{abstract}

\section{Introduction}

With the development of the policy to implement geological disposal of nuclear waste in the UK, and the quest for a suitable location or locations for the Geological Disposal Facility (GDF), short- and long-term passive and remote monitoring of the bentonitebased Engineered Barrier System (EBS), typical of a number of disposal concepts, has emerged as a key issue. As part of a major Engineering and Physical Sciences Research Council-Nuclear Decommissioning Authority (EPSRC-NDA)-sponsored research consortium focused on the monitoring of EBS, the capability of selected permanent magnets to be employed to detect the evolution of groundwater chemistry within the EBS is being investigated. The commercial N42-grade $\mathrm{NdFeB}$ alloy magnet was chosen to investigate the variation in magnetic properties with time as a consequence of reactions and corrosion. The final aim was to develop a sensor that may be monitored remotely. From the perspective of the integrity of the EBS, the 
question of whether the corrosion processes, which enable magnetic monitoring, affect negatively the performance of the bentonite buffer itself, must also be asked.

Bentonite has been chosen as a buffer material by several national nuclear-waste management companies because of its swelling capacity and low water permeability, and because it retards the transport of radionuclides and corrosion products toward the geosphere (Madsen, 1998).

The interaction between bentonite and iron $(\mathrm{Fe})$ has been investigated to model montmorillonite stability and the evolution of the waste canister-bentonite buffer interface through time (Wilson et al., 2006; Marty et al., 2010) and its dependence on alkalinity (Charpentiera et al., 2006) or salinity (Milodowski et al., 2007).

Corrosion of Fe-bearing materials leads to precipitation of microcrystalline oxyhydroxides as common products in a first aerobic corrosion during which all oxygen available in the system is consumed. This is followed by anaerobic corrosion which is said to determine the long-term behavior of the canister/bentonite system (Kaufhold et al., 2015). At temperatures of $<100^{\circ} \mathrm{C}$, smectites are transformed into Fe-smectites or $7 \AA$ phases (berthierine) (Kaufhold et al., 2015). Above $150^{\circ} \mathrm{C}$, they transform into $14 \AA$ phases (chlorite, saponite) (Wersin and Mettler, 2006; Wersin et al., 2008).

\section{Materials and methods}

The present study investigated the effects of corrosion of permanent NdFeB magnets on natural Na-bentonite MX80 from Wyoming (USA), previously characterized by Madsen (1998) and Pusch (2006). Compacted MX80 clay 'doughnuts' were supplied by RS minerals (Cleveland, UK) and ClayTechAB (Lund, Sweden). Phase quantification was given by Madsen (1998).

The corrosion of the NdFeB magnets (grade N42 NdFeB permanent alloy) within the bentonite buffer was investigated in a saturated and sealed environment, using deionized water, chloride $\left(1 \mathrm{M} \mathrm{NaCl}, \mathrm{KCl}\right.$, and $\left.\mathrm{CaCl}_{2}\right)$, and hydroxide $(0.1 \mathrm{M} \mathrm{NaOH}$ and $\mathrm{KOH}$, and $0.05 \mathrm{M} \mathrm{Ca}(\mathrm{OH})_{2}$ ) solutions. The 5-month experiment (at a constant temperature of $70^{\circ} \mathrm{C}$ ) was performed using $50 \mathrm{~mL}$ borosilicate glass serum bottles, filled with powdered MX80 Na-bentonite mixed with fragments (size ranging from $5 \mathrm{~mm}$ to $1 \mathrm{~cm}$ ) of $\mathrm{NdFeB}$ magnets (clay:magnet volume ratio 19:1) and aqueous solution (solution accounted for $70 \%$ and solids for $30 \%$ of the volume). The bottles were left with $25 \%$ void space and were sealed using butyl rubber septa and high-temperature resistant silicon paste.

The resultant clays were sampled at the magnet-matrix (bentonite) interface washing the magnet with acetone. Clays were prepared as oriented mounts on glass slides, and then analyzed, after air drying and glycol solvation as described by Moore and Reynolds (1997), using a Bruker (Coventry, UK ) D8 Advance Diffractometer with a sol-x energy dispersive detector and $\mathrm{CuK} \alpha$ radiation (measurement range $=2-70^{\circ} 2 \theta$, step size $=0.02^{\circ} 2 \theta$, step time $=1.5 \mathrm{~s}$ ). Background removal was performed by means of an automatic function and calibration using the quartz 001 peak at $26.6^{\circ} 2 \theta$. The bentonite samples reacted with saline waters $\left(1 \mathrm{M} \mathrm{NaCl}, \mathrm{KCl}\right.$, and $\left.\mathrm{CaCl}_{2}\right)$ contained precipitated Fe-(oxyhydr)oxides which were digested using a dithionite-citrate system buffered 
with $\mathrm{Na}$ bicarbonate (after Mehra and Jackson, 1958). The same specimens were also sampled in areas outside the visible reaction haloes to evaluate any changes in the areas unaffected by Fe-(oxyhydr)oxide precipitation.

\section{Results and discussion}

Samples reacting in saline environments showed corrosion effects (Figure 1) resulting in disaggregated magnet fragments. A red halo at the bentonite-water interface became a distinguishing feature, fading to a yellow to greenish gray color toward the bentonite matrix. This was due to precipitation of Fe (oxyhydr)oxides during aerobic corrosion.

The sample reacting with deionized water showed disaggregation of the magnets, but featured no reddish halo in the matrix. Interestingly, samples reacting in alkaline environments showed only partial oxidation of the magnets, with the formation of a layer of oxyhydroxides $\left(\mathrm{Nd}(\mathrm{OH})_{3}\right.$ and $\left.\mathrm{FeOOH}\right)$ on the magnet's surface, as measured using semi-quantitative X-ray diffraction (XRD). The study of oxides and oxyhydroxides is not immediately relevant to the present study; these are addressed by Rigonat et al. (2015). The XRD patterns of air-dried and ethylene-glycolated clays collected from the deionized water-treated sample showed the series of basal reflections characteristic of Na-montmorillonite and, thus, shifted toward lower diffraction angles after glycol solvation (Figure 2).

The XRD pattern of the air-dried samples after reaction with alkaline solutions (Figure 3) revealed slightly asymmetric 001 reflections centered at $12.6 \AA$ for the bentonites reacted in $\mathrm{NaOH}$ solution. $\mathrm{KOH}$ solution-treated samples showed peaks centered

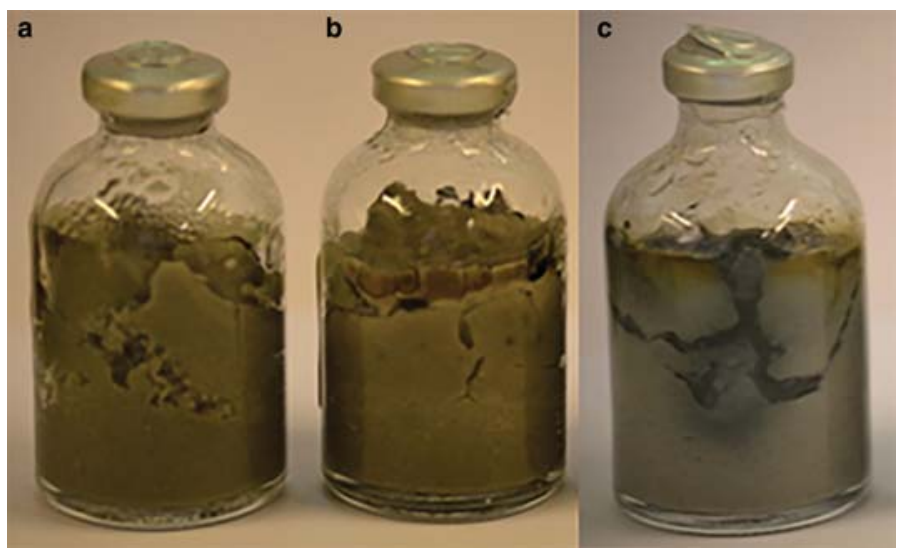

Figure 1. Post-extraction pictures of $\mathrm{NdFeB} /$ bentonite mixtures reacted with (a) distilled water, (b) $0.1 \mathrm{M}$ $\mathrm{Na}(\mathrm{OH})$ solution, (c) and $1 \mathrm{M} \mathrm{NaCl}$ solution. The red patina visible in the samples in the middle and on the right is caused by precipitation of $\mathrm{Fe}$ (oxyhydr)oxides. 


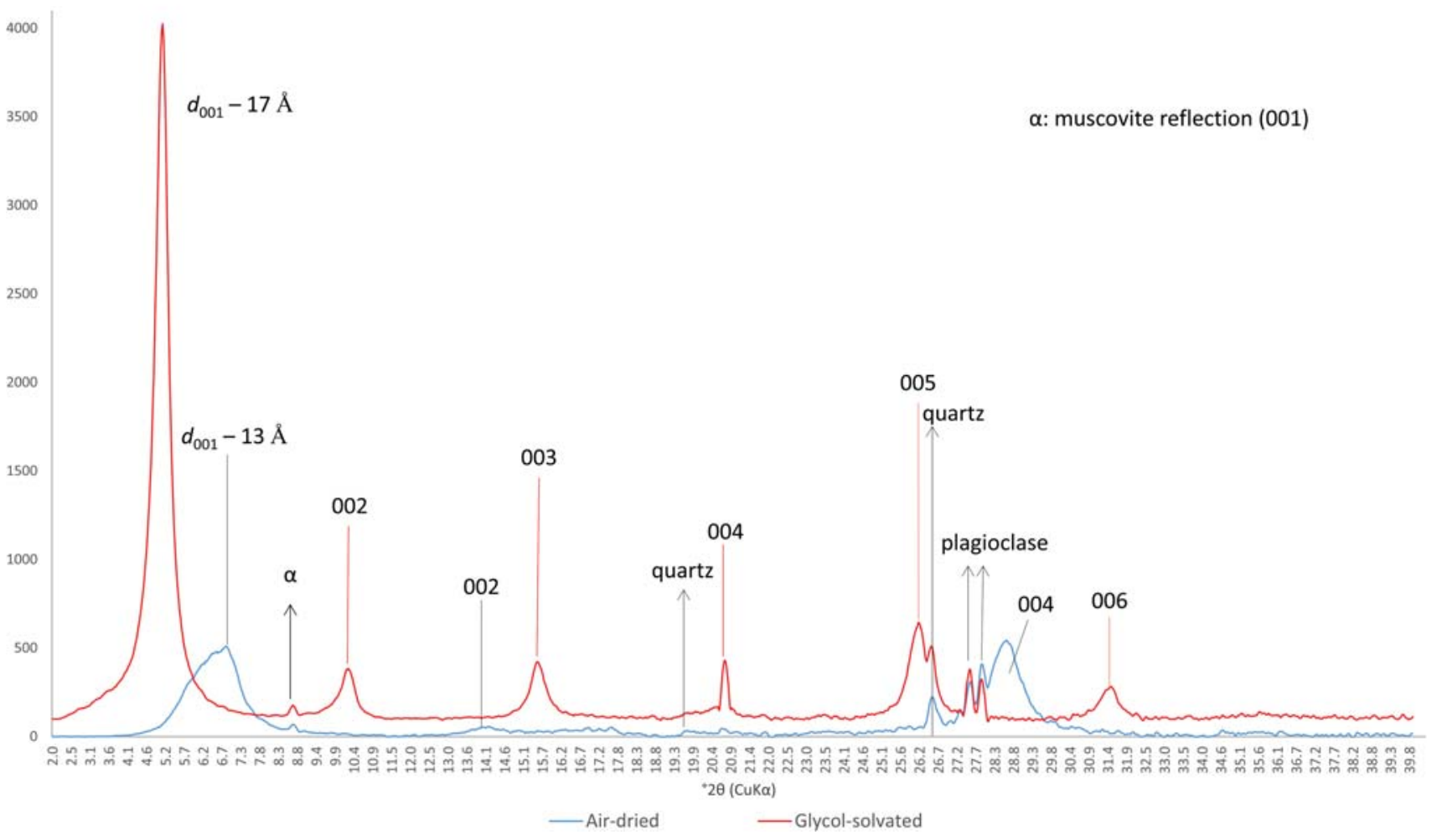

Figure 2. XRD traces of air-dried (blue) and glycol-solvated (red) clay from a Na-montmorillonite/NdFeB mixture reacted with deionized water. Red lines relate to reflections of ethylene-glycolated samples, black lines to air-dried samples, and black arrows to accessory minerals. 


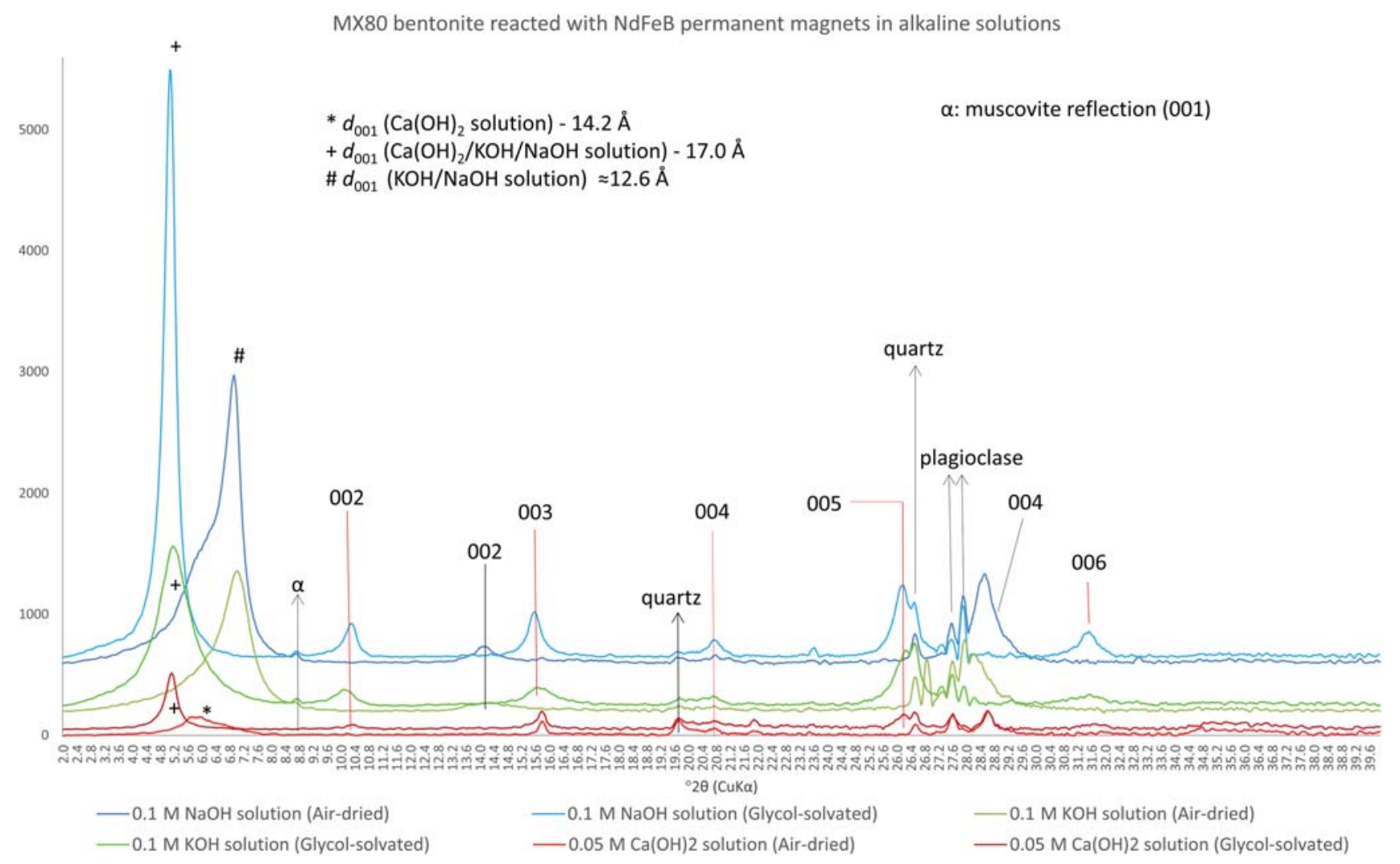

Figure 3. XRD traces of air-dried and glycol-solvated clays from Na-montmorillonite/NdFeB mixture reacted with alkaline solutions. Red lines relate to reflections of ethylene-glycolated samples, black lines to air-dried samples, and black arrows to accessory minerals. 


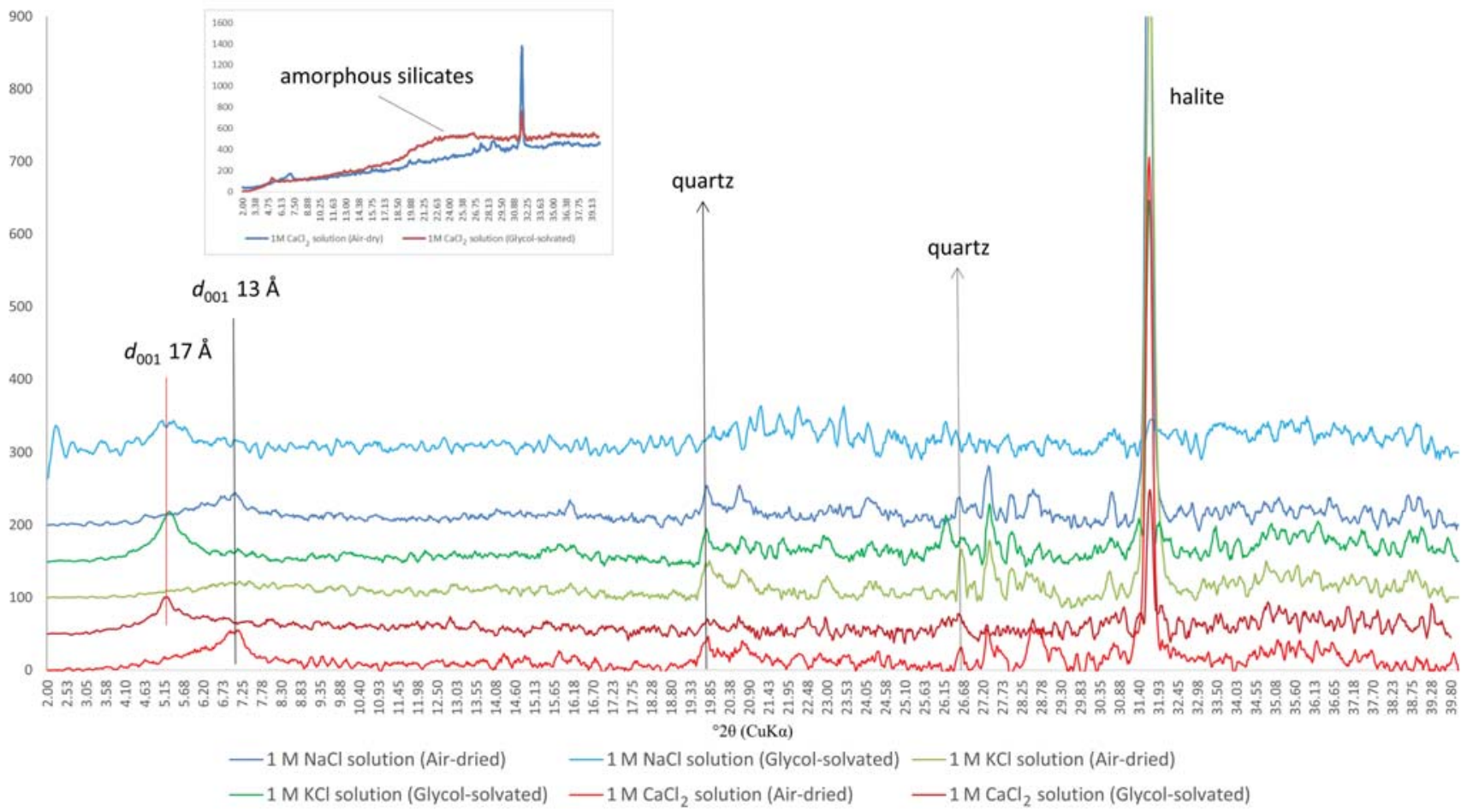

Figure 4. XRD traces of air-dried and glycol-solvated clays from Na-montmorillonite/NdFeB mixture reacted with saline solutions and sampled at the magnet/ matrix interface. The traces were all smoothed and the background removed. An example of trace without background removal is displayed in the inset figure. All the 001 reflections are very small and broad (the air-dried KCl-solution trace is flat) but increase slightly in intensity and shift toward lower diffraction angles after glycol solvation. Red lines relate to reflections of ethylene-glycolated samples, black lines to air-dried samples, and black arrows to accessory minerals. 
MX80 bentonite reacted with NdFeB permanent magnets in saline waters

clays sampled outside the reaction halo

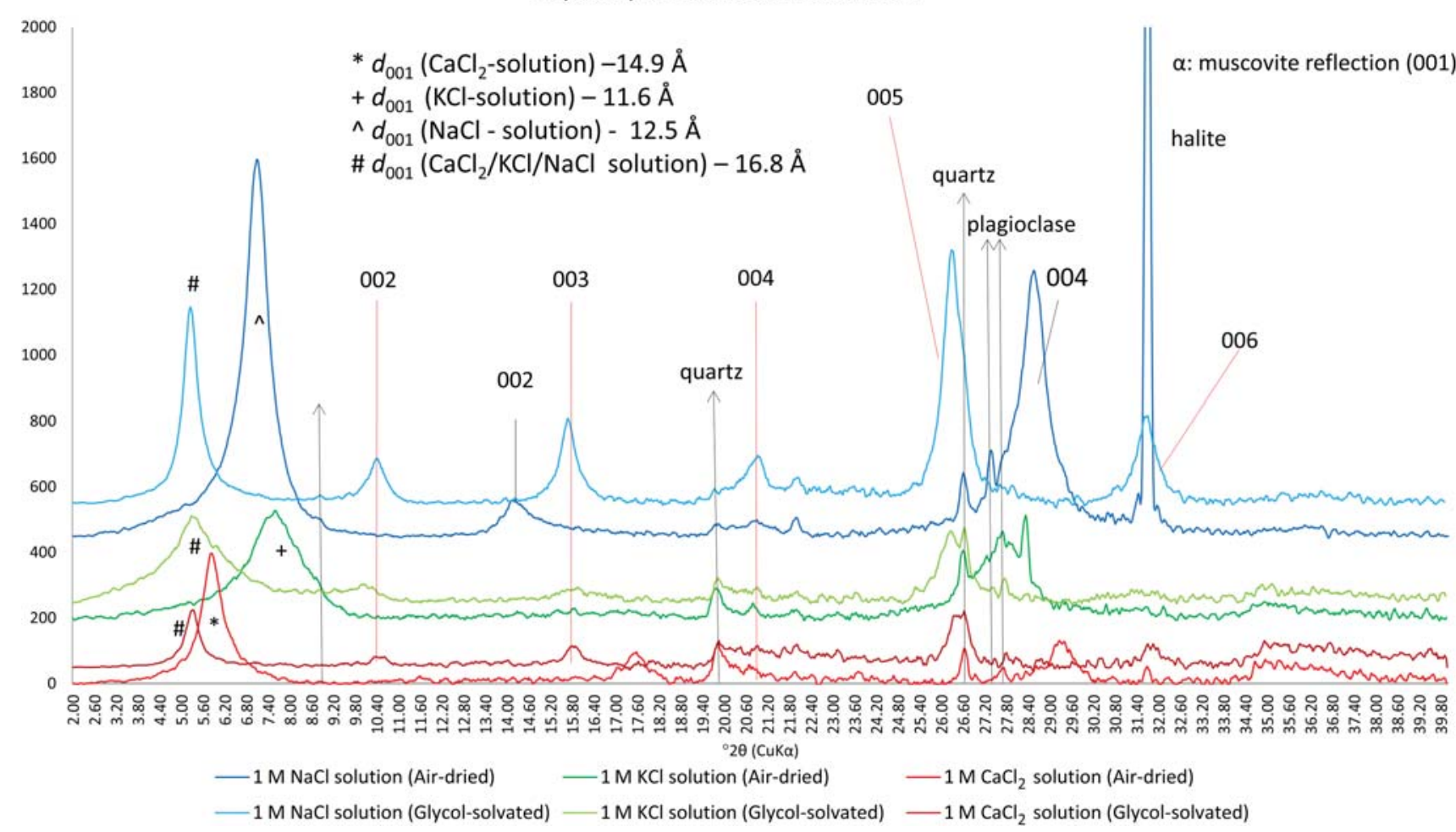

Figure 5. XRD traces of air-dried and glycol-solvated clays from Na-montmorillonite/NdFeB mixture reacted with saline solutions and sampled in the unaltered matrix. The positions of 001 reflections in the air-dried traces of $\mathrm{KCl}$ - and $\mathrm{NaCl}$-solution treated samples $(\sim 1 \mathrm{w})$ show significant deviation from the $\mathrm{CaCl}{ }_{2}$ watertreated sample $(\sim 2 \mathrm{w})$ but they were all centered at $16.8 \AA$ after glycol solvation. Red lines relate to reflections of ethylene-glycolated samples, black lines to air-dried samples, and black arrows to accessory minerals. 
at slightly higher diffraction angles. The $\mathrm{Ca}(\mathrm{OH})_{2}$ solution-reacted bentonite contained a weaker and broader basal 001 reflection centered at $14.2^{\circ} 2 \theta$. All of the traces collected after glycol solvation showed a shift of the first basal reflection toward lower diffraction angles (corresponding to a $d$ value of $17.0 \AA$ ) and also a sharpening of the peaks. The different behavior of the air-dried $\mathrm{Ca}(\mathrm{OH})_{2}$ solution-treated sample with respect to the others is explained by the formation of interstratified Ca-Na-montmorillonite (McAtee, 1956)

The clays collected at the magnet-matrix interface in the samples reacted with chloride solutions showed very weak or flat reflections (Figure 4). The pattern for air-dried samples exhibited peak intensities which were 20 times lower than the samples in Figures 3 and 5. The 001 reflections from the glycol-solvated samples were sharper and slightly more intense, but still rather low. The traces without background removal showed a hump typical of amorphous silicates (Figure 4, inset).

The XRD patterns (Figure 5) of clays sampled in the matrix unaffected by corrosion or leaking of $\mathrm{Fe}$ revealed that the basal reflections for the air-dried $\mathrm{KCl}$ - and $\mathrm{CaCl}_{2}$-Solution-treated samples were decreased significantly compared with the $\mathrm{NaCl}$-solution reacted sample. The $d_{001}$ value increased to $16.8 \AA$ upon glycol solvation (Figure 5) and the glycol-solvated, $\mathrm{KCl}$-treated sample had a broad peak that is well known for K-exchanged smectites.

\section{Summary and conclusions}

Tests on the NdFeB-bentonite mixtures showed that, after an initial period of aerobic corrosion which led to the deposition of Fe (oxyhydr)oxides at the solution-clay interface, the process switched to anaerobic corrosion ( $c f$. Kaufhold et al., 2015) which was particularly evident in samples corroded within chloride solutions. Powder XRD analyses run on the clays sampled in the corrosion-affected area in saline-treated samples revealed no reflections typical of Fe-bearing smectites, although their presence, as weakly crystallized phases, cannot be excluded. The changes in the samples reacted with K-rich solutions can be related to different cation:water ratios in the interlayer space due to $\mathrm{K} / \mathrm{Na}$ cation exchange.

The changes in the positions of the peaks were attributed exclusively to K-Na and $\mathrm{Ca}-\mathrm{Na}$ cation exchange in the interlayer; hence, the observed transformations are only related to the initial composition of the solution.

The clays collected at the magnet-matrix interface in the samples showing the most intense effects of corrosion, displayed very weak and broad basal reflections even after glycol solvation. These weak and broad reflections are thought to be related to a lowtemperature dissolution/reprecipitation process. Broad, weak maxima are produced by the combination of the fine particle size and poor crystallinity with complex random interstratification (as found in soil profiles by Brown and Jackson, 1956). These clays formed at the interface, in a silica gel matrix, might represent a step of pure Na-montmorillonite evolution toward an Fe-enriched member proceeding from an aerobic to an anaerobic environment. 
Experimental results indicate that under the environmental conditions applied, the corrosion of the $\mathrm{NdFeB}$ magnets is different, going from alkaline to saline, circum-neutral environments. The corrosion process does not cause a loss of performance of the clay in terms of swelling, as no corrosion-related, neoformed, non-swelling clay minerals were detected and all the changes in the bentonite matrix were related exclusively to the initial water composition.

\section{Acknowledgments}

The present study was undertaken with funding from Radioactive Waste Management Limited (RWM) (http://www.nda.gov.uk/rwm), a wholly-owned subsidiary of the Nuclear Decommissioning Authority. RWM is committed to the open publication of such work in peer reviewed literature, and welcomes e-feedback to rwmdfeedback@nda. gov.uk. Many thanks to Dr Nicholas Odling for technical support with the XRD equipment.

\section{Guest editor: Reiner Dohrmann}

The authors and editors are grateful to anonymous reviewers who offered very helpful input and suggestions. A list of all reviewers is given at the end of the Preface for this volume.

\section{References}

Brown, B. and Jackson, M. (1956) Clay Mineral Distribution in the Hiawatha Sandy Soils of northern Wisconsin. National Academy of Sciences, USA, Washington D.C.

Charpentiera, D., Devineau, K., Mosser-Ruck, R., Cathelineau, M., and Villieras, F. (2006) Bentonite-iron interactions under alkaline condition: an experimental approach. Applied Clay Science, 32, 1-13.

Kaufhold, S. and Dohrmann, R. (2009) Stability of bentonites in salt solutions: sodium chloride. Applied Clay Science, 45, 171-177.

Kaufhold, S., Hassel, A., Sanders, D., and Dohrmann, R. (2015) Corrosion of high-level radioactive waste iron-canisters in contact with bentonite. Journal of Hazardous Materials, 285, 464-473.

Madsen, F. (1998) Clay mineralogical investigations related to nuclear waste disposal. Clay Minerals, 33, $109-129$.

Marty, N., Fritz, B., Clement, A., and Michau, N. (2010) Modelling the long term alteration of the engineered bentonite barrier in an underground radioactive waste repository. Applied Clay Science, 47, 82-90.

McAtee, J. (1956) Determination of random interstratification in montmorillonite. American Mineralogist, 41, $627-631$.

Mehra, O. and Jackson, M. (1958) Iron oxide removal from soils and clays by a dithionite-citrate system buffered with sodum bicarbonate. Clays and Clay Minerals, 7, 317-327.

Milodowski, A., Cave, M., Kemp, S., Taylor, H., Vickers, B., Green, K., Williams, C.L., and Shaw, R. (2007) Mineralogical investigations of the interaction between iron corrosion products and bentonite form the NF-PRO experiments (Phase 1). British Geological Survey, Nottingham, UK.

Moore, D. and Reynolds, R. (1997) X-ray Diffraction and the Identification and Analysis of Clay Minerals ( $2^{\text {nd }}$ edition). Oxford University Press, New York.

Pusch, R. (2006) Clays and nuclear waste management. Pp. 703-716 in: Handbook of Clay Science ((F. Bergaya, B.K.G. Theng, and G. Lagaly, editors). Elsevier Ltd., Amsterdam.

Rigonat, N., Harley, S., Butler, I., and Bromiley, G. (2015) Monitoring fluid evolution in an engineered barrier system using NEO-magnets. American Geophysical Union 2015 Fall Meeting, San Francisco. 
Wersin, P. and Mettler, S. (2006) Worksop on Fe-clay interactions in repository environments, a joint initiative by ANDRA, SKB and NAGRA. Arbeitsbericht NAB 06-15.

Wersin, P., Snellmann, S., and Riekkola, O. (2008) Impact of iron on the performance of clay barriers in waste disposal systems. Report on the status of research and development. SKB, Stockholm.

Wilson, J., Savage, D., Cuadros, J., Shibata, M., and Ragnasdottir, K.V. (2006) The effect of iron on montmorillonite stability. (I) Background and thermodynamic considerations. Geochimica et Cosmochimica Acta, 70, 306-322. 